\title{
ФОРМИРОВАНИЕ ГРУЗИНСКОЙ НАЦИОНАЛЬНОЙ ИДЕИ
}

\section{FORMATION OF THE GEORGIAN NATIONAL IDEA}

\section{P. Lebedeva}

Summary: Based on the modernist concept of the theory of nationalism, the emergence of the modern Georgian national idea dates back to the middle of the 19th century. The article examines the historical context of that period, and also analyzes the main ideas that influenced the formation of the Georgian national identity.

Keywords: national identity, national culture, Georgia, Georgian culture, Ilya Chavchavadze, theories of nationalism, constructivism, modernism.
Лебедева Параскева Викторовна

Аспирант, Санкт-Петербургский государственный университет paraskevalebedeva@mail.ru

Аннотация: Исходя из модернистской концепции теории национализма, возникновение современной грузинской национальной идеи датируется серединой XIX в. В статье рассматривается исторический контекст того периода, а также анализируются основные идеи, повлиявшие на формирование грузинской национальной идентичности.

Ключевые слова: национальная идентичность, национальная культура, Грузия, грузинская культура, Илья Чавчавадзе, теории национализма, конструктивизм, модернизм.
И сходя из утверждения теории конструктивизма что нация - это проект Нового времени, истоки современной грузинской национальной идеи проявляются в середине XIX в. В данной статье история возникновения грузинской национальной идентичности рассматривается, главным образом, в рамках одной из значительных теорий национализма возникшей в XX-м в. - теории конструктивизма. Главное отличие конструктивизма от примордиализма заключается в том, что конструктивизм рассматривает нацию, как сознательно сформированную реальность, а не как изначальную данность. Широкое распространение конструктивизм получил к 70-80-м гг. XX в. и наибольшую популярность приобрел в США, Канаде и Австралии.

Для представителей конструктивистского подхода характерно рассмотрение нации, как результата целенаправленной осознанной деятельности. Политическая деятельность признается главным фактором формирования нации как общности. Конструирующая роль государства совмещается с наличием доброй воли граждан, а также с необходимыми предпосылками (уровень культурной гомогенности и образованности общества).

Теория конструктивизма наглядно показывает, что национализм, который является сложным массовым явлением, распадается на отдельные составляющие элементы, которые можно выявить и рассмотреть.

Ф. Барт выводит на первый план аспект осознания принадлежности к этнической группе. Он определяет этнические группы, как формы социальной организации, которые приписывают идентичность себе и другим. Этнические границы создаются с помощью социальных процессов включения и исключения, которые члены групп сами определяют как значимые или нет (допуска- ется исключение радикального сходства или различия), т.е. этнические границы формируются вследствие межэтнических контактов и взаимосвязей $[9$, с. 20].

Один из основателей конструктивизма, Эрнест Геллнер, подчеркивает необходимость всеобщего образования в процессе создания нации. Сама идея национализма конструируется именно в процессе образования, где формируется национальная культура: «национализм использует существовавшие до этого культуры и культурные богатства, хотя использует их избирательно и, чаще всего, радикально их трансформирует. Мертвые языки могут быть оживлены, традиции - изобретены, вполне фиктивная первоначальная чистота нравов - восстановлена» [2, с.127].

Б. Андерсон в своей знаменитой книге «Воображаемые сообщества» (англ. «Imagined Communities: Reflections on the Origin and Spread of Nationalism») предлагает рассматривать нацию, как «воображенное сообщество». Для конструирования такого общества элиты обычно используют такие средства как единый национальный литературный язык, национальную литературу, прессу, географические карты, перепись населения, музеи и пр.

Андерсон рассматривает нацию как явление одного рода с такими культурными явлениями как «родство» или «религия». У нации есть своя история и будущее. Роль нации возрастает по мере того, как приходит в упадок религия, и в обществе происходят изменения способов восприятия окружающей действительности. Особенно Андерсон выделяет развитие печатного капитализма, которое способствовало формированию необходимого для «воображаемого сообщества» коммуникационного поля. 
Один из главных критиков теории конструктивизма, ученик Э. Геллнера, этносимволист Э. Смит, отмечает, что важную роль в очерчивании культурной идентичности играют интеллектуалы и люди умственного труда, так как именно они ставят на первое место категорию нации: «С помощью своих образов и символов они описывают и репрезентируют для других значение и особый характер нации» $[6$, с. 177].

Одним из факторов обострения национального грузинского самосознания послужил процесс включения грузинских княжеств в состав Российской Империи. Началом этого поэтапного процесса стало подписание Георгиевского трактата в 1783 г. [4, с. 41], согласно которому царь Картли-Кахетии (территории восточной Грузии), Ираклий II, признавал над собой верховную власть России во внешней политике, при этом правительство Российской Империи гарантировало свое невмешательство во внутреннюю политику грузинского царства. Согласно договору, должны были соблюдаться обычные правила престолонаследия от отца к сыну, но в 1800 г. после смерти сына Ираклия II, Георгия XII, российский император Павел I не стал утверждать на царство его сына Давида, а вместо этого опубликовал манифест об упразднении Картлийско-Кахетинского царства. Окончательно это решение было закреплено новым манифестом уже при Александре I в 1801-1802 гг., территория грузинского царства получили статус губерни («Грузинская губерния» до 1840 г.), управление которой осуществлял чиновник с должностью «управляющий Грузией».

Параллельно с присоединением восточной Грузии аналогичный процесс в 1803-1810 гг. происходил и на территории западной Грузии, которая на тот момент представляла из себя разрозненную территорию без единого политического управления. Поэтапно к территории Российской Империи были присоединены Имеретинское царство (1810), Мегрельское (1803) и Гурийское (1804) княжества.

В культурном поле первыми национальную тему подняли грузинские поэты-романтики. На их поэзии выросло поколение грузинской аристократии, оформившее идею современного грузинского самосознания. [11, с. 69]. Так и писатель Дмитрий Кипиани и поэт Александр Чавчавадзе принимали участие в заговоре грузинского дворянства в 1832 г. целью которого было освобождение Грузии от власти Российской Империи, за что и были сосланы в Вологду и Тамбов соответственно.

Первые лидеры грузинской национальной идеи получили образование в столичном Петербурге, так среди них И. Чавчавадзе, А. Церетели, Г. Церетели, Н. Николадзе А. Церетели и др., которые в 60-70-х гг. XIX в. создали в Грузии общество Тергдалеулеби (тергдалеулни груз. олґъœьмээмо - испившие воду Терека). Этот термин применялся к молодёжи 2 -ой половины XIX века, которая отправлялась по ту сторону реки Терек - в Россию для получения образования), целью которого было национальное и социальное освобождение грузинского народа. Деятельность общества была направлена на распространение грамотности среди населения Грузии, финансирование школ и театров, издания учебной литературы и пр.

Видными участниками «тергдалеулеби» были Дм. Кипиани, Нико Николадзе, Георгий Церетели, Акакий Церетели, Якоб Гогебашвили и др. (позже к ним примкнули Сергей Месхи, Важа Пшавела и др.). Лидером «шестидесятников» ещё при жизни стал - Илья Чавчавадзе.

В современной Грузии фигура И. Чавчавадзе обладает колоссальным авторитетом, особенное внимание стоит уделить его определению грузинской нации, которое считается классическим постулатом.

Илья Чавчавадзе (1837 - 1907) как и многие другие грузинские аристократы того времени учился в России, в 1857 г. он поступил на Юридический факультет Императорского университета в Петербурге, но в 1861 г. был исключен из-за участия в антиправительственных забастовках. Вернувшись в Грузию, он занялся широкой просветительской деятельностью. Он является одним из основателей Общества распространения грамотности среди грузинского населения (1879 г.), которое боролось, в том числе, и с тотальной русификацией в Грузии. В правление Александра III грузинский язык был исключен из школьной программы, за исключением некоторых приходских школ[6, с. 273]. При этом чиновники Российской Империи умело играли на процессах консолидации грузинского этноса, поощряя развитие сванского и мегрельских языков в Западной Грузии. Члены общества активно занималась распространением грузинского языка среди населения, описанием памятников древнегрузинской литературы, собиранием фольклора, учреждением первых грузинских гимназий. Один из видных основателей общества. Якоб Гогебашвили, составил первые обучающие пособия - «Алфавит грузинского языка и первая книга для чтения для учеников»;

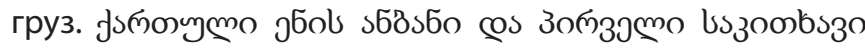

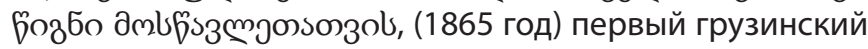
букварь «Дэда эна» («Родной язык») груз. œэœs јб s, (1876 год).

В своих литературных трудах Чавчавадзе и его сторонники способствовали формированию современного литературного грузинского языка, также они осуществили реформирование алфавита (убрав пять архаичных букв).

Главным полем деятельности И. Чавчавадзе стало издание грузиноязычной газеты «Иверия» (1877-1906), 
основателем и главным редактором которой долгое время являлся он сам. Именно на страницах «Иверии» Чавчавадзе и его сторонники высказывали свои взгляды о судьбе Грузии, а также вели полемику с оппонентами.

Исследователи внимательно рассматривают лирику и публицистику Чавчавадзе в поисках «первых ласточек» его понимания грузинской национальной идеи [8, с. 61]. Характерной иллюстрацией служит рассказ «Записки проезжего от Владикавказа до Тифлиса» 1861 г., повествующий о возвращении главного героя из столицы в родную Грузию. Автор размышляет о своей предстоящей встрече с родиной, как она его примет? Отвергнет ли она его, как человека оставившего её или признает за своё дитя? Герой приходит к заключению, что он всё же будет принят и признан за своего, но теряется при мысли, что его страна потребует от него конкретных действий. Именно в «Записках» проявляются характерные аспекты грузинской национальной идеи того времени такие как желание независимости и государственного суверенитета, конфликт между традицией и современностью, убежденность в необходимости модернизации и пр.

В 1860 Илья Чавчавадзе предложил свою знаменитую триаду: «Три божественных сокровища осталось у нас от отцов и дедов: Родина, Язык, Религия. Если всем этим не овладеем, какой ответ отдадим потомкам» [2, с.24]. Эта триада стала лозунгом грузинской национальной идеи и остаётся им до сих пор. Каждый из элементов триады является нациообразующим компонентом, маркером грузинской идентичности. [10, с.89].

В своих трудах Илья Чавчавадзе обозначал проблему разобщенности грузинской нации, он ратовал за общее национальное самосознание всего народа, которое, по его мнению, достигается общей историей: «По нашему мнению, ни единство языка, ни единство религии и даже ни родство людей друг с другом не могут объединить так, как объединяет единство истории» [5, с. 17].

\section{Выво $\Delta ы$}

Проанализируем основные моменты формирования грузинской национальной идеи.

1. Решающая роль в формировании национального самосознания принадлежит элите.

Современное грузинское самосознание возникло и развилось в кругах писателей молодого поколения 60-х80 гг. Группой молодых грузинских дворян, получивших образование в Российской Империи, называющих себя «тергдалеулеби», велась активная просветительская и общественная деятельность.

\section{2. Особенная роль национального языка.}

И. Чавчавадзе и его сторонниками было развернуто движение, направленное на развитие грузинского языка. Было проведено реформирования письма, закрепление новых литературных норм, приближенных к разговорному языку, что способствовало более широкому распространению грузинского языка, как светского. Также участники «тергдалеулеби» способствовали распространению грамотности среди населения.

3. Маркеры грузинской идентичности. И. Чавчавадзе сформулировал основную триаду грузинской национальной идеи - Родина, Язык, Религия. Именно вокруг этих маркеров в дальнейшем развивалась идея национального грузинского самосознания.

Интеллектуальные основы грузинской национальной идеи были заложены поколением «тергдалеулеби», они послужил фундаментом для дальнейшего развития идей национально-грузинского самосознания. Этот процесс формирования идеологии грузинской национальной идеи обозначил культурные границы грузинского единства, выявил основные маркеры национальной идентичности и стал важнейшим этапом формировании базовых ценностей, символов и смыслов грузинской нации.

\section{ЛИТЕРАТУРА}

1. Андерсон Б. Воображаемые сообщества. Размышления об истоках и распространении национализма. - М.: Кучково поле, 2016. - 416 с.

2. Буадзе Т., Христианские ценности и общественно-политическое устройство // Гули гониери. 2017. № 18. с. $24-42$.

3. Геллнер э. Нации и национализм. - М.: Прогресс, 1991. - 794 с.

4. Грузины / отв. ред. Л.К. Бериашвили, Л.Ш. Меликишвили, Л.Т. Соловьева; Ин-т этнологии и антропологии им. Н.Н. Миклухо-Маклая РАН; Национальная академия наук Грузии; Комиссия по истории, археологии и этнологии НАН Грузии. - М.: Наука, 2015. - 813 с.

5. История Грузии. Т. 2. С 60-х годов ХІХ века до 1921 г.: Учеб. пособие под ред. Н. А. Бердзенишвили. - 1973. - 331 с.

6. Рейфилд Д., Грузия. Перекресток империй. История длиной в три тысячи лет. - М.: КоЛибри, Азбука-Аттикус, 2017. - 608 с.

7. Смит Э. Национализм и модернизм: Критический обзор современных теорий наций и национализма. - М.: Праксис, 2004. - 464 с.

8. Чхартишвили М., Грузинская национальная идея в рамках европейского дискурса о феномене нации // Европейские ценности и идентичность. 2014. С.

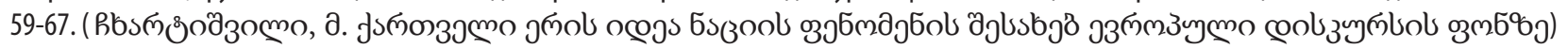


9. Чхартишвили М., Освещение процесса национальной консолидации грузин в печатных СМИ: Иверия и Грузия, как ее читатель. - Тбилиси: Универсали,

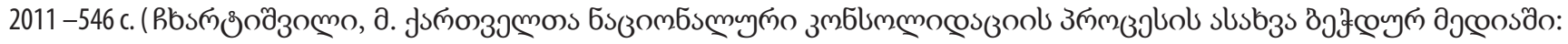

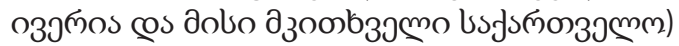

10. Этнические группы и социальные границы: Социальная организация культурных различий: Сборник статей / Под ред. Ф. Барта; пер. с англ. И. Пильщикова. М.: Новое издательство, 2006. 200 c.

11. Nodia G, Components of the Georgian National Idea: An Outline. // Identity studies. 2009. № 1. pp. 84-101.

12. Sabanadze N., Globalization and Nationalism: The Cases of Georgia and the Basque Country. - Budapest: Central European University Press, 2010 -218 p.

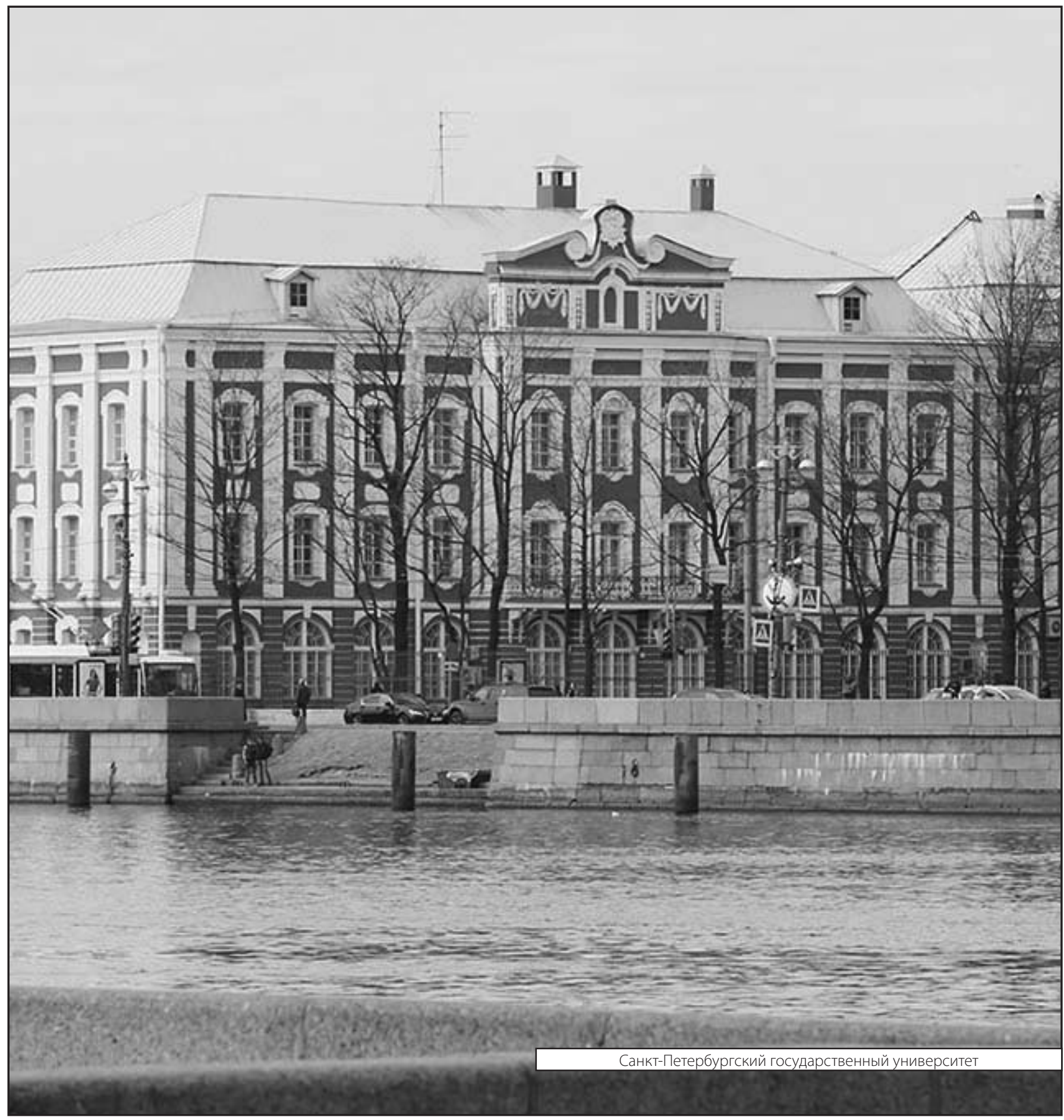

